\section{Localized alveolar osteitis: the role of suture technique following disimpaction of mandibular third molars in a Nigerian Teaching Hospital}

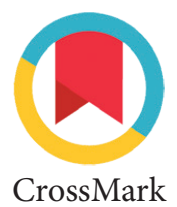

\author{
Thomas Owobu, ${ }^{1}$ Auwal S. Balarabe, ${ }^{2}$ Sylvester Nwabueze, ${ }^{3}$ \\ Babatunde O. Bamgbose ${ }^{4 *}$
}

CrossMark

\title{
Abstract
}

Objective: The formation of localized alveolar osteitis following mandibular third molar disimpaction is a result of a complex interaction between systemic factors, local infection and surgical trauma. This study evaluates the relationship between wound closure techniques in the development of localized alveolar osteitis (Dry Socket) following disimpaction of mandibular third molar teeth in Aminu Kano Teaching Hospital.

Material and Methods: A total of 120 patients between the ages of 18 and 45 years were recruited into the study. A gender ratio of male to female, $1.07: 1$, was recorded. They were then divided into two groups (A \& B) according to wound closure technique used. Group A had suture-less/partial wound closure and Group B had complete wound closure technique. Data were analyzed using SPSS version 20.0 (SPSS Inc, (hicago IL), with simple descriptive statistics and the $X^{2}$ text, as appropriate. $P<.05$ was considered significant.

Results: A total number of 23 patients (7.2\%) developed localized alveolar osteitis from both groups. The prevalence of localized alveolar osteitis was higher in patients who received suture-less/partial wound closure technique $(91.3 \%)$, while $(8.7 \%)$ developed dry socket in complete wound closure technique. The difference between the two group was statistically significant $(p<0.05)$.

Conclusion: This study revealed that wound closure technique following disimpaction of mandibular third molar teeth is a major factor in the development of localized alveolar osteitis.
${ }^{1}$ Department of Dental and Maxillofacial, Federal Medical Center, Nguru, Yobe State ${ }^{2}$ Department of Child Dental Health, Faculty of Dentistry, Bayero University Kano, Kano

${ }^{3}$ Nigerian Army Level 11 Hospital, Damaturu, Yobe State

${ }^{4}$ Department of Oral Diagnostic Sciences, Faculty of Dentistry, Bayero University Kano, Kano

*Correspondence to: Babatunde 0. Bamgbose, Department of Oral Diagnostic Sciences, Faculty of Dentistry, Bayero University Kano, Kano drtundebamgbose@yahoo.com

Received: 12 April 2019 Revised: 14 May 2019 Accepted: 18 August 2019 Available Online 1 December 2019
Keywords: Localized alveolar osteitis, Third molar disimpaction, Wound closure technique

Cite this Article: Owobu T, Balarabe AS, Nwabueze S, Bamgbose B0. 2019. Localized alveolar osteitis: the role of suture technique following disimpaction of mandibular third molars in a Nigerian Teaching Hospital. Journal of Dentomaxillofacial Science 4(3): 128-132. D0I: 10.15562/jdmfs. v4i3.937

\section{Introduction}

Localized alveolar Osteitis (Dry Socket) is a recognized and a common complication following tooth extraction. ${ }^{1-3}$ It develops as a result a breakdown of blood clot in the extraction socket. Clinically, it is characterized by severe pain around the extraction sites with associated exposed bony walls of the extraction socket, high sensitivity on gentle probing and a foul-smelling odor with occasional lodgment of food debris inside the extraction socket. ${ }^{4,5}$ These clinical symptoms usually begin from the fifth day post disimpaction. ${ }^{6-8}$ The first description of localized alveolar osteitis as 'Dry Socket' was by Crawford ${ }^{6}$ in 1896 . Other terms presently used include postoperative alveolitis, septic socket, delayed extraction wound healing, fibrinolytic alveolitis, alveolar sicca dolorosa, necrotic socket and localized osteomyelitis.

The formation of localized alveolar osteitis following mandibular third molar disimpaction is a result of a complex interaction between systemic factors, local infection and surgical trauma. ${ }^{8-12}$ Notable among these factors are intraoperative complications such as alveolar bone fracture, root fracture, surgical difficulty, wound closure technique, ${ }^{11,12}$ and, in some few cases, patient's non- adherence to post-disimpaction instructions. Findings from literature have suggested an increase in the frequency of localized alveolar osteitis following tooth extraction in female. Studies have shown that patients who had mandibular third molar disimpacted as a result of caries, infection and cystic lesion are more likely to develop localized alveolar osteitis than patients who had their disimpaction for prophylactic reasons. ${ }^{13-21}$ The risk of developing localized alveolar osteitis and other postoperative compilations have been noted to be higher in smokers and females who use oral contraceptive drugs, but not much has been recorded of the suture techniques following mandibular third molar dismpaction. However, the incidence of localized alveolar osteitis can be reduced to $2-8 \%$ by the application of mediations such as metronidazole, tetracycline, clindamycin, chlorhexidine mouth rinse and local antiseptic pack following mandibular third molar disimpaction. ${ }^{22-25}$

The aim of this study was to evaluate the role of wound closure technique in the development of localized alveolar osteitis among patients who had 
third molar disimpaction at Aminu Kano Teaching Hospital, Kano, Nigeria.

\section{Material and Methods}

This study was conducted amongst consenting patients between the ages of 18 and 45 years that presented in our oral surgery and dental retainership clinics for surgical extraction of their impacted mandibular third molars. Patients with bleeding disorder, facial cellulitis, breast feeding women and patients who were receiving treatment with analgesic, anti-inflammatory treatment (both steroidal and non- steroidal anti-inflammatory) were excluded from the study.

Ethical approval for the study was provided by Aminu Kano Teaching Hospital Ethical Review Committee. (AKTH/MAC/SUB/12A/P-3/VI/1443)

The surgical extraction was carried out in the Oral and Maxillofacial Surgery Clinics of the Aminu Kano Teaching Hospital (AKTH), Kano. Patients who met the inclusion criteria were randomly allocated into two groups by simple balloting (random

Table 1 Social demographic characteristic of patients

\begin{tabular}{|c|c|c|}
\hline Description of & Complete closure $\mathbf{n}(\%)$ & $\begin{array}{l}\text { Partial closure } \\
\text { techniquen (\%) }\end{array}$ \\
\hline \multicolumn{3}{|l|}{ Age } \\
\hline $18-25$ & $8(13.30)$ & $9(15.0)$ \\
\hline $26-35$ & $36(60.0)$ & $36(60.0)$ \\
\hline 36 and above & $16(26.70)$ & $15(25.0)$ \\
\hline \multicolumn{3}{|l|}{ Gender } \\
\hline Male & $33(55.0)$ & $29(48.0)$ \\
\hline Female & $27(45.0)$ & $31(52.0)$ \\
\hline \multicolumn{3}{|l|}{ Occupation } \\
\hline Civil Servants & $18(30.0)$ & $22(36.7)$ \\
\hline Housewives & $8(13.3)$ & $10(16.6)$ \\
\hline Students & $25(41.7)$ & $21(35.0)$ \\
\hline Business/Traders & $9(15)$ & $7(11.7)$ \\
\hline \multicolumn{3}{|l|}{ Tribe } \\
\hline Ibo & $6(10.0)$ & $5(8.3)$ \\
\hline Yoruba & $4(6.7)$ & $3(5)$ \\
\hline Hausa & $25(41.7)$ & $27(45.0)$ \\
\hline Fulani & $24(40.0)$ & $25(41.7)$ \\
\hline Others & $1(1.6)$ & $0(0)$ \\
\hline \multicolumn{3}{|c|}{ Educational qualification } \\
\hline Quaranic & $12(20.0)$ & $14(23.3)$ \\
\hline Primary & $2(3.3)$ & $3(5.0)$ \\
\hline Secondary & $4(6.7)$ & $6(10.0)$ \\
\hline Polytechnic & $5(8.3)$ & $3(5.0)$ \\
\hline University & $37(61.7)$ & $34(56.7)$ \\
\hline
\end{tabular}

sampling). In group I (partial wound closure) the flap was repositioned and sutured with one or two stitches (silk 3-0) with the soft and hard tissues still maintaining their anatomical configuration. In group II (complete wound closure) the socket was hermetically closed by rotating the mesial mucoperiosteal flap and sutured over the socket to the mucoperiostium on the lingual side to cover the extraction socket. The mean duration of surgery from incision to completion of suturing was recorded in minutes.

All patients received postoperative instructions and were placed on amoxicillin, 500mg 8 hourly for 5 days, metronidazole $400 \mathrm{mg} 8$ hourly for 5 days and diclofenac sodium 50mg 12 hourly for 3 days, to prevent possible wound infections and pain.

The patients were evaluated for signs and symptoms of dry socket $3 \mathrm{rd}$, 7th and 10th postoperative days with the aid of a questionnaire. Information collected included patient's demographics, pattern of impaction, reasons for surgical extraction and presence or absent of postoperative symptoms of dry socket formation.

The data was analyzed using statistical package for social sciences (SPSS) version 20.0 (SPSS Inc, Chicago, IL). Absolute numbers and simple percentages were used to describe categorical variables. Quantitative variables were described using measures of central tendency (mean, median) and measures of dispersion (range, standard deviation) as appropriate. No tests of significance were done.

\section{Results}

A total of 120 research participants were recruited into the study. Mean age of the participants was 31.7 \pm 5.7 . Most patients fell within the 26 to 35 -year-old age groups. Table 1 the overall gender distribution was almost even; there were $51.7 \% \quad(n=62)$ males and $48.3 \% \quad(n=58)$ females. The subjects were made up of students $38.3 \% \quad(n=46)$, civil servants $33.4 \% \quad(n=40)$, housewives $15.0 \%(\mathrm{n}=18)$ and business owners/ traders $13.3 \% \quad(n=16)$. The Hausa and Fulani ethnic groups have almost equal number of representations in the study with $51(42.5 \%)$ and $48(40.0 \%)$ respectively. The other ethnic groups, Ibo $10.0 \%(n=12)$, Yoruba $6.7 \%(n=8)$ and others $0.8 \%(n=1)$ represented a smaller percentage in the study population table 1.

A total number of 23 patients (7.2\%) developed localized alveolar osteitis from both groups. In group I (suture-less/partial wound closure), 21 patients $(91.3 \%)$ developed dry socket while 2 patients $(8.7 \%)$ developed dry socket in group II (complete wound closure technique). Table 2 and table 3. 
Table 2 Distribution of localized alveolar osteitis according to gender

\begin{tabular}{llllc}
\hline & & M & F & Total \\
\hline Localized alveolar osteitis & Present (+ve) & 10 & 13 & 23 \\
& Absent (-ve) & 52 & 45 & 97 \\
Total & & 62 & 58 & 120 \\
\hline
\end{tabular}

Table 3 Distribution of localized alveolar osteitis according to wound closure technique

\begin{tabular}{lccc}
\hline \multicolumn{4}{c}{ Wound Closure Techniques } \\
\hline & Suture-less/partial suture & Complete suture & Total \\
\hline & 60 & 60 & \\
Present $(+\mathrm{ve})$ & 21 & 2 & $23(19.2 \%)$ \\
Absent (-ve) & 39 & 58 & $97(80.8 \%)$ \\
Total & 60 & 60 & $120(100 \%)$ \\
\hline
\end{tabular}

\section{Discussion}

The development of localized alveolar osteitis (dry socket) following mandibular third molar disimpaction has been a source of pain and discomfort, which has negative impact and adversely affects patient's quality of life (QoL). It is a serious challenge and of great concern to the dental surgeons. ${ }^{26-28}$ Because of this and other long-term morbidity following mandibular third molar disimpaction, some countries had to develop management protocol for mandibular third molars. ${ }^{29}$ Surgeons must weigh the benefit as well as explain in details the possible complications to patients before the procedure. ${ }^{30}$

Disimpaction of impacted mandibular third molar is one of the most frequently performed procedures in oral surgery clinic. ${ }^{30-31}$ This surgical intervention involves traumatic injury to adjacent soft and bony tissues with resultant postoperative complications; such as pain, swelling, limitation of mouth opening and local alveolitis. ${ }^{30}$ Studies have shown that the severity of the postoperative complications varies and they can significantly influence patient's quality of life for days. ${ }^{31}$ This immediate postoperative complication is as a result of inflammatory response secondary to trauma. ${ }^{30}$ The intensity of this trauma-induced inflammatory response and the resultant post-operative complication has been attributed to various factors; such as age and gender of the patient, the degree of impaction, surgical method, soft tissue handling as well as wound closure techniques. ${ }^{31-35}$

Literature review on the morbidity following surgical removal of mandibular third molar indicates that factors that increase the risk of operative difficulty of the impacted tooth significantly will also increase postoperative inflammatory pain and swelling as well as local alveolitis. It means an older female patient, above 30 years, with a horizontally impacted tooth may have increased duration of surgery and a more severe postoperative complication as a consequence. ${ }^{34,36}$

In a standard setting, the commonest method for the removal of mandibular third molars consist of flap development (buccal extension flap, envelope flap or triangular flap), bone removal, luxation and tooth removal. Once an appropriate flap is reflected, the next logical progression is the removal of bone around the tooth, which is carried out by use of a mallet and chisel or Guttering Teachnique. ${ }^{37}$ Depending on the level of the third molar impaction, bone is removed from the occlusal, buccal and distal positions as required. In some cases with distoangular impactions, bone may need to be removed from the mesial aspect. The use of lingual bone split technique has also been advocated, but this method is not routinely used as it is often associated with more postoperative complications with a higher incidence of lingual nerve injury. ${ }^{37-39}$

Surgical removal of mandibular third molar like any other surgical procedures may result in iatrogenic trauma to soft and hard tissues with moderate to severe inflammatory response. This position is corroborated by data obtained from previous studies which show that the incidence of postoperative complication is related to the degree of surgical trauma as well as the size of mucoperiosteal flap raised during the procedure. ${ }^{34}$ for example, most patients report lesser incidences of postoperative local alveolitis when a small incision is made during flap development, with minimal reflection of the mucoperiosteum. ${ }^{39-4}$

After a third molar surgery, the wound can either be left alone (suture-less), ${ }^{36}$ closed partially or closed completely as the case may require. Though some authors advocated a suture-less technique, ${ }^{40-41}$ This is not a common practice in our clinics as no surgeon feels comfortable leaving extraction socket of surgically extracted mandibular third molar open without a single suture. In the complete wound closure technique, the socket is hermetically closed by rotating the mesial mucoperiosteal flap and sutured over the socket to the mucoperiostium on the lingual side to cover the extraction socket. It has been said that, the completely closed socket does not allow free drainage of this inflammatory exudate, which may lead to significant swelling and pain postoperatively. ${ }^{41}$ However, comparative studies on the effect of wound closure techniques on complications after impacted mandibular third molar surgery show minimal variation on the severity of postoperative pain and swelling using different 
closure methods. ${ }^{36}$ this technique does not allow food debris accumulation inside the extraction socket. For the partial wound closure technique, one or two interrupted sutures are applied to reposition the mucoperiosteal flap raised, the soft and hard tissues still maintaining their anatomical configuration with socket still communicating with the oral cavity. ${ }^{35-36}$ Findings from various literature show that a partially closed socket allows free drainage of inflammatory exudate thereby reducing postoperative pain and swelling. The draw back with this technique is that it allows accumulation of food debris which may infect the wound which may ultimately leads to the formation of local alveolitis.

The formation of localized alveolar osteitis following mandibular third molar disimpaction is as a result of a complex interaction between systemic, local infection and surgical trauma. Other factors that could influence the formation of localized alveolar osteitis are the intraoperative complications such as alveolar bone fracture, root fracture, surgical difficulty and, in some few cases, patients' non- adherent to post-disimpaction instructions. The increase of fibrinolytic activity within the socket and interaction of many other factors have been reported. Though the exact pathophysiology and etiology of localized alveolar osteitis is not yet understood, studies have identified other risk factors which can contribute to its occurrence in most patients. ${ }^{19,20}$ The risk factor include patients with poor oral hygiene practice, surgical difficulty, surgeons' experience, use of oral contraceptive, tobacco smoking, female gender and flap design. However, the exact mechanism by which most of these risk factors influence the development of dry socket in most patients is still not understood. Findings from the present study show that wound closure technique, irrespective of other variables, was a major determinant in the development dry socket amongst the patients that underwent disimpaction of mandibular third molar teeth in our study. ${ }^{42}$ An example was a case of a 39-year-old man who presented with bilateral mesioangular impacted mandibular molars. There was no caries on either tooth. Patient was not a known smoker nor had any systemic diseases. One side was surgically extracted with the socket completely closed and three months later the other side was also surgically removed with the socket partially closed. The patient developed dry socket on the partial closed extraction socket.

This study however, does not in any way invalidate findings from different literature from various authors the role of gender, surgeon's experience, tobacco smoking, use of oral contraceptive and all other factors that have so far be implicated in the development localized alveolar osteitis. ${ }^{22}$ However, identification of predisposing factors and application of preventing measure is a key to the overall success in the management of dry socket. ${ }^{43}$

\section{Conclusion}

This study showed that wound closure technique following disimpaction of mandibular third molar teeth play a major role in the development of localized alveolar osteitis. Though much work still needs to be done in this area, it is the authors' belief that the relationship between wound closure technique and dry socket formation deserve further investigation.

\section{Acknowledgment}

None

\section{Conflict of Interest}

The authors expressed no conflicts of interest with this study.

\section{References}

1. Peterson LJ, Ellis E III, Hupp JR, et al. Contemporary oral and maxillofacial surgery. 3rd ed. St. Louis: Mosby; 1998. p. 215-48.

2. Wong JD. Alveolar osteitis: a review. Sydney: Dentistry Library University of Sydney; 1993.

3. Alexander RE. Dental extraction wound management: a case against medicating postextraction sockets. J Oral Maxillofac Surg 2000;58: 538-551.

4. Erickson RI, Waite DE, Wilkison RH. A study of dry sockets. Oral Surg Oral Med Oral Pathol 1960;13: 1046-1050.

5. Oluseye SB. Exodontia: a retrospective study of the reasons, methods and complications of tooth extraction in oral and maxillofacial surgery clinic, Lagos University Teaching Hospital. NPMC dissertation. National postgraduate medical college of Nigeria 1993.

6. Awang MN. The aetiology of dry socket: a review. Int Dent J 1989;39: 236-240.

7. Noroozi AR, Philbert RF. Modern concepts in understanding and management of the "dry socket" syndrome: comprehensive review of the literature. Oral Surg Oral Med Oral Pathol Oral Radiol Endod 2009;107: 30-35.

8. Saheeb BD, Obuekwe ON. An audit of mandibular third molar surgery. Nig J Surg Res 2001;3: 66-74

9. Belinfante LS, Marlow CD, Myers W, et al. Incidence of dry socket complication in third molar removal. J Oral Surg 1973;31: 106-108.

10. Kumar V, Chaudhary M, Singh S, et al. Post-surgical evaluation of dry socket formation after surgical removal of impacted mandibular third molar-a prospective study. Open J Stomatol 2012.

11. Anighoro EO, Gbotolorun OM, Adewole RA, et al. Assessment of the effect of wound closure technique on postoperative sequelae and complications after impacted mandibular third molar extraction. Open J Stomatol 2013;3: 527-532.

12. Jabber JK. A comparison between primary and secondary wound closure after surgical removal of lower third molars according to pain and swellin. MDJ 2008. 
13. Schow SR. Evaluation of postoperative localized osteitis in mandibular third molar surgery. Oral Surg, Oral Med, Oral Pathol 1974;38: 352-358.

14. Birn H. Etiology and pathogenesis of fibrinolytic alveolitis (dry socket). Int J Oral Surg 1973;2: 215.

15. Fridrich KL, Olson RAJ. Alveolar osteitis following surgical removal of mandibular third molars. Anesth Prog 1990;37: 32-41.

16. Lilly GE, Osbon DB, Rael EM, et al. Alveolar osteitis associated with mandibular third molar extractions. J Am Dent Assoc 1974;88: 802-806.

17. Larsen PE. Alveolar osteitis after surgical removal of impacted mandibular third molars: Identification of the patient at risk. Oral Surg, Oral Med, Oral Pathol 1992;73: 393-397.

18. Sweet JB, Butler DP. Effect of smoking on the incidence of localized osteitis following mandibular third molar surgery. Quintessence Int 1978;9: 7-10.

19. Sweet JB, Butler DP. predisposing and operative factor: effect on the incidence of localized osteitis in mandibular third molar surgery. Oral Surg 1978;46: 206.

20. Blum IR. Contemporary views on dry socket (alveolar osteitis): A clinical appraisal of standardization, aetiopathogenesis and management: a critical review. Int J Oral \& Maxillofac Surg 2002;31: 309-317.

21. Al-Belasy FA. The relationship of "shisha" (water pipe) smoking to postextraction dry socket. J Oral Maxillofac Surg 2004;62: 10-14.

22. Cohen ME, Simecek JW. Effects of gender-related factors on the incidence of localized alveolar osteitis. Oral Surg Oral Med Oral Pathol Oral Radiol Endod 1995;79: 416.

23. Swanson AE. Reducing the incidence of dry socket: a clinical appraisal. J Dent Assoc S Afr 1966;21: 155-162.

24. Sorensen DC, Preisch J. The effect of tetracycline on the incidence of postextraction alveolar osteitis. J Oral Maxillofac Surg 1987;45: 1029.

25. Fotos P, Koorbusch GF, Sarasin D, et al. Evaluation of intraalveolar chlorhexidine dressing after removal of impacted mandibular third molars. Oral Surg Oral Med Oral Pathol 1992;73: 383.

26. McGrath C, Comfort MB, Lo EC, et al. Changes in quality of life following third molar surgery- the immediate postoperative period. Br Dent J 2003;194: 265-268.

27. Pederson A. Inter-relationship of complaints after removal of impacted third molars. Int J Oral Maxillofac Surg 1985; 14: 241-247.

28. Chiapasco M, De Cicco L, Marrone G. Side effects and complications associated with third molar surgery. Oral Surg Oral Med Oral Pathol 1993;76: 412-420.

29. American Association of Oral Maxillofacial Surgeons: Report of a workshop on the management of patients with third molar teeth. J Oral Maxillofacial Surg 2013;52: 1102.
30. National Institute of Dental Research. Removal of Third Molars. NIH Consensus Development Program Statement; 1979. p. 65-68.

31. Archer WH. Oral and Maxillofacial Surgery. 5th ed. Philadelphia: WB Sounders Co.; 1975. p. 321-335.

32. Blondeau F, Daniel MG. Extraction of impacted mandibular third molars: postoperative complications and their risk factors. J Can Dent Assoc 2007;73: 235-325.

33. Adeyemo WL, Bamgbose BO, Obi EV, et al. Effect of age, impaction types and operative time on inflammatory tissue reactions following lower third molar surgery. Head Face Med 2011;7: 8-11.

34. Peterson LJ, Ellis E III, Hupp JR, et al. Management of impacted teeth. Contemporary Oral and Maxillofacial Surgery. 3rd ed. St. Louis: Mosby; 1998. p. 215-248.

35. Fisher SE, Frame JW, Route PGJ. Factors affecting the onset and severity of pain following the surgical removal of unilateral impacted mandibular third molar teeth. Bri Dent J 1998;164: 351-357.

36. Julia F, Newton G, Jon L. Differences in postoperative pain severity among four ethnic groups. J Pain Symptom Manag1994;9: 383-389.

37. Saheeb BD, Obuekwe ON. An audit of mandibular third molar surgery. Nig J Surg Res 2001;3: 66-74.

38. García GA, Gude SF, Gallas TM, et al. Trismus and pain after removal of a lower third molar. Effects of raising a mucoperiosteal flap. Med Oral 2001;6: 391-396.

39. Suddhasthira T, Chaiwat S, Sattapongsda P. A comparative study of primary and secondary closure techniques after removal of impacted mandibular third molars. Thai J Oral \& Maxillofac Surg 1991;5: 67-77.

40. Osunde OD, Adebola RA, Saheeb BD. A comparative study of the effect of suture-less and multiple suture techniques on inflammatory complications following third molar surgery. Int J Oral Maxillofac Surg 2012;41: 1275-1279.

41. McGrath C, Comfort MB, Lo EC, et al. Changes in quality of life following third molar surgery- the immediate postoperative period. Br Dent J 2003;194: 265-268.

42. Du-Bois DD, Pizer ME, Chinnis RJ. Comparison of primary and secondary closure techniques after removal of impacted mandibular third molars. J Oral Marillofac Surg 1982;4: 631-634.

43. Trieger N, Schlagel GD. Preventing dry socket. A simple procedure. J Am Dent Assoc 1991;122: 67.

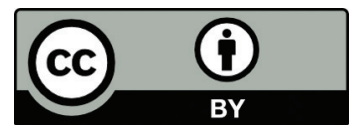

This work is licensed under a Creative Commons Attribution 